\title{
EFEKTIVITAS LAYANAN KONSELING KELOMPOK TEKNIK MANAJEMEN DIRI UNTUK MENINGKATKAN SELF-ESTEEM SISWA
}

\author{
Ni Komang Sri Yuliastini ${ }^{1)}$, I Made Mahaardhika ${ }^{2)}$ \\ ${ }^{1)}$ Prodi Bimbingan dan Konseling, FIP IKIP PGRI Bali \\ Email:yuliastini_nks@ymail.com \\ ${ }^{2)}$ Prodi Bimbingan dan Konseling, FIP IKIP PGRI Bali \\ Email:maha_made@yahoo.com
}

\begin{abstract}
Abstrak. Tujuan penelitian ini adalah mengetahui kondisi self-esteem siswa dan mengetahui keefektifan layanan konseling kelompok teknik manajemen diri untuk meningkatkan self-esteem siswa kelas X SMK PGRI 1 Denpasar. Jenis penelitian ini adalah penelitian kuantitatif.Penelitian ini melibatkan 6 siswa sebagai sampel. Berdasarkan hasil uji lapangan, tingkat self esteem siswa mengalami peningkatan setelah mengikuti kegiatan konseling kelompok dengan teknik manajemen diri. Ditunjukkan dengan perubahan tingkat efikasi diri siswa sebelum diberikan perlakuan (evaluasi awal) dan sesudah (evaluasi akhir) sebesar 103 poin. Hasil didukung data hasil perhitungan dengan uji ratarata uji wilcoxon yang menunjukkan nilai hitung 0,026 sehingga dapat disimpulkan bahwa layanan konseling kelompok dengan teknik manajemen diri efektif untuk meningkatkan self esteem siswa.
\end{abstract}

Kata Kunci: Konseling Kelompok; Manajemen Diri; Self-Esteem

\section{PENDAHULUAN}

Seseorang yang memiliki harga diri tinggi akan mampu mengenal dan memahami diri sendiri. Sementara itu, memiliki harga diri rendah dapat menghambat pengembangan potensi diri. Jadi orang yang memiliki harga diri rendah akan menjadi seseorang yang pesimis dalam menghadapi tantangan, takut dan ragu-ragu untuk menyampaikan gagasan, bimbang dalam menentukan pilihan dan sering membanding-bandingkan dirinya dengan orang lain. Memiliki harga diri yang tinggi sangat berpengaruh dalam melakukan sosialisasi karena adanya kemampuan untuk mengenal, menghadapi bermacam-macam karakter orang, menginterpretasikan dan memberikan tanggapan yang tepat terhadap berbagai situasi sosial, serta mampu memadukan kebutuhannya sendiri dengan harapan orang lain atas dirinya.

Hasil wawancara guru BK yang penulis terima dari guru BK kelas $\mathrm{X}$ diperoleh informasi bahwa banyak siswa yang menunjukkan gejala kurang percaya diri. Gejala tersebut nampak pada perilaku seperti tidak berani mengajukan pertanyaan atau pendapat, tidak bersedia tampil di depan kelas, kurang menghargai pendapat, cemas ketika akan menghadapi ujian atau tes, berbicara gugup, menghindarkan diri ketika akan ditanya guru dan berteman hanya dengan orang-orang tertentu. Layanan KKp dengan teknik manajemen diri dapat secara langsung siswa berlatih menciptakan dinamika kelompok, yakni melatih berbicara, menghargai, menanggapi, mendengarkan dan bertenggang rasa dalam suasana kelompok. Kegiatan ini merupakan tempat pengembangan diri dalam rangka belajar meningkatkan self-esteem secara efektif dalam kelompok kecil.

Konseling kelompok adalah salah satu layanan bimbingan konseling yang dilakukan oleh konselor (pemimpin kelompok) terhadap sekelompok konseli (anggota kelompok) yang bermasalah agar permasalahannya terselesaikan dan potensinya dapat berkembang optimal [1]. Teknik manajemen diri merupakan suatu teknik untuk pengubahan dan pengembangan perilaku yang menekankan pentingnya ikhtiar dan tanggung jawab pribadi untuk mengubah dan mengembangkan perilakunya sendiri [2]. Pengubahan perilaku ini dalam prosesnya lebih banyak 
dilakukan oleh individu (konseli) yang bersangkutan, bukan diarahkan atau bahkan dipaksakan oleh orang lain (konselor).

\section{METODE}

Jenis penelitian ini adalah penelitian kuantitatif. Penelitian kuantitatif adalah penelitian yang berlandaskan filsafat positivisme, digunakan untuk meneliti pada populasi atau sampel tertentu [3]. Teknik pengambilan sampel pada umumnya dilakukan secara random, pengumpulan data menggunakan instrument penelitian. Analisis data bersifat kuantitatif/ statistik dengan tujuan untuk menguji hipotesis yang telah ditetapkan. Subjek penelitian adalah SMK PGRI 1 Denpasar. Objek penelitan adalah siswa kelas $\mathrm{X}$ yang ditetapkan menjadi kelompok eksperimen yang ditentukan secara purposive sampling. Penelitian ini menggunakan dua metode penelitian yaitu kualitatif dan kuantitatif secara terpadu. Penelitian dilakukan dalam tiga tahap kegiatan, yaitu:

1. Tahap persiapan, meliputi: perumusan masalah, menentukan jenis informasi yang diperlukan, menentukan sampel penelitian, menentukan prosedur pengumpulan data, menentukan prosedur pengolahan informasi atau data.

2. Tahap pelaksanaan kegiatan adalah memberikan layanan konseling kelompok teknik manajemen diri untuk meningkatkan self-esteem siswa.

3. Tahap analisis data adalah mengumpulkan, menganalisis dan membuat kesimpulan dari data yang diperoleh pada tahap pelaksanaan.

\section{HASIL DAN PEMBAHASAN}

A. HASIL

Tinggi rendahnya self esteemsiswa diukur dengan skala psikologis yang terdiri dari 5 indikator yang dijabarkan pada 60 butir dan 42 butir yang teruji validitasnya dengan jumlah siswa 160. Kategori yang digunakan untuk menentukan self esteemadalah tinggi, sedang, rendah, sangat rendah. Pelaksanaan intervensi dan subjek penelitian dilaksanakan di SMK PGRI 1 Denpasar dengan pertimbangan bahwa dari 5 indikator self esteem, banyak dialami oleh siswa SMK PGRI 1 Denpasar. Penelitian ini dilaksanakan di SMK PGRI 1 Denpasar. Sebelum disebarkan kepada siswa, skala self esteemagar teruji efektif, maka diperlukan adanya uji kelayakan secara rasional dilakukan melalui penilaian pakar. Ahli atau pakar yang menjadi validator merupakan seorang Doktor pada bidang Bimbingan dan yang memiliki sejumlah temuan hasil penelitian. Hasil uji kelayakan ahli diperoleh 67 skor. Skor ini menunjukkan instrument yang dikembangkan berada pada kategori sangat baik. Berdasarkan studi pendahuluan, observasi dan kajian penelitian terdahulu maka penerapan isi konseling kelompok dengan teknik manajemen diri untuk meningkatkan self esteem siswa diinternalisasikan dengan mengintegrasi permasalahan-permasalahan sesuai dengan self esteem siswa pada tabel I.

TABEL I

INDIKATOR, SASARAN DAN PERLAKUAN

\begin{tabular}{|c|c|c|c|c|}
\hline $\begin{array}{c}\text { Pelaksanaan } \\
\text { Kegiatan }\end{array}$ & $\begin{array}{c}\text { Target } \\
\text { Intervensi }\end{array}$ & Tujuan & Kegiatan & Indikator Keberhasilan \\
\hline $\begin{array}{l}\text { Kegiatan } \\
\text { Pendahuluan }\end{array}$ & $\begin{array}{l}\text { - Pemantapan } \\
\text { mengikuti } \\
\text { kegiatan } \\
\text { - Perumusan } \\
\text { tujuan yang } \\
\text { ingin dicapai }\end{array}$ & $\begin{array}{l}\text { - Terciptanya hubungan } \\
\text { yang baik antara } \\
\text { peneliti dengan } \\
\text { anggota kelompok } \\
\text { - Perkenalan, } \\
\text { penerimaan, serta } \\
\text { merinci dan menyusun } \\
\text { tujuan pelaksanaan } \\
\text { konseling kelompok }\end{array}$ & $\begin{array}{l}\text { - Mengajak siswa mengikuti } \\
\text { kegiatan konseling } \\
\text { kelompok secara aktif, } \\
\text { nyaman dan tanpa adanya } \\
\text { perasaan paksaan }\end{array}$ & $\begin{array}{l}\text { - Siswa bersedia mengikuti } \\
\text { kegiatan konseling kelompok } \\
\text { - Terjadinya kesepakatan yang } \\
\text { baik antara peneliti dan konseli } \\
\text { mengenai agenda dan tujuan } \\
\text { pelaksanaan konseling } \\
\text { kelompok } \\
\text { - Terjadinya hubungan antara } \\
\text { anggota anggota satu dengan } \\
\text { yang lain. }\end{array}$ \\
\hline KKp 1 & $\begin{array}{l}\text { - Sence of } \\
\text { Security }\end{array}$ & $\begin{array}{l}\text { - Sejauh mana anak } \\
\text { merasa aman dalam } \\
\text { bertingkah laku dan } \\
\text { tidak takut disalahkan }\end{array}$ & $\begin{array}{l}\text { - Mengidentifikasi sejauh } \\
\text { mana anak berani bertindak } \\
\text { dan mengemukakan } \\
\text { pendapat } \\
\text { - Menumbuhkan minat anak } \\
\text { akan keinginan bersaing } \\
\text { secara sehat }\end{array}$ & $\begin{array}{l}\text { - Siswa mampu mengidentifikasi } \\
\text { sejauh mana anak berani } \\
\text { bertindak dan mengemukakan } \\
\text { pendapat } \\
\text { - Siswa dapat menumbuhkan } \\
\text { minat anak akan keinginan } \\
\text { bersaing secara sehat }\end{array}$ \\
\hline KKp 2 & $\begin{array}{l}\text { - Sence of } \\
\text { Identity }\end{array}$ & $\begin{array}{l}\text { - Kesadaran anak } \\
\text { tentang sejauh mana } \\
\text { potensi, kemampuan } \\
\text { dan keberartian tentang } \\
\text { dirinya sendiri }\end{array}$ & $\begin{array}{l}\text { - Menanamkan keyakinan } \\
\text { bahwa dirinya mampu lebih } \\
\text { baik dari orang lain } \\
\text { - Melakukan introspeksi diri } \\
\text { apabila mengalami }\end{array}$ & $\begin{array}{l}\text { - Siswa menanamkan keyakinan } \\
\text { bahwa dirinya mampu lebih } \\
\text { baik dari orang lain } \\
\text { - Siswa dapat melakukan } \\
\text { introspeksi diri apabila }\end{array}$ \\
\hline
\end{tabular}




\begin{tabular}{|c|c|c|c|c|}
\hline & & & $\begin{array}{l}\text { kegagalan } \\
\text { - Memiliki pikiran yang } \\
\text { positif akan dirinya }\end{array}$ & $\begin{array}{l}\text { mengalami kegagalan } \\
\text { - Siswa memiliki pikiran yang } \\
\text { positif akan dirinya }\end{array}$ \\
\hline KKр 3 & $\begin{array}{l}\text { - Sense of } \\
\text { Belonging }\end{array}$ & $\begin{array}{l}\text { - Perasaan yang muncul } \\
\text { karena anak merasa } \\
\text { sebagai bagian dari } \\
\text { kelompoknya }\end{array}$ & $\begin{array}{l}\text { - Aktif dalam organisasi } \\
\text { sekolah } \\
\text { - Mudah bergaul dengan } \\
\text { siapa saja tanpa } \\
\text { membedakan status atas } \\
\text { kedudukan }\end{array}$ & $\begin{array}{l}\text { - Siswa aktif dalam organisasi } \\
\text { sekolah } \\
\text { - Siswa mudah bergaul dengan } \\
\text { siapa saja tanpa membedakan } \\
\text { status atas kedudukan }\end{array}$ \\
\hline KKр 4 & $\begin{array}{l}\text { - Sense of } \\
\text { Purpose }\end{array}$ & $\begin{array}{l}\text { - Keyakinan individu } \\
\text { bahwa dirinya akan } \\
\text { berhasil mencapai } \\
\text { tujuan yang } \\
\text { diinginkan, merasa } \\
\text { memiliki motivasi }\end{array}$ & $\begin{array}{l}\text { - Berusaha untuk menjadi } \\
\text { lebih baik } \\
\text { - Menerima keadaan hidup }\end{array}$ & $\begin{array}{l}\text { - Siswa berusaha untuk menjadi } \\
\text { lebih baik } \\
\text { - Siswa menerima keadaan hidup }\end{array}$ \\
\hline KKр 5 & $\begin{array}{l}\text { - Sense of } \\
\text { Personal } \\
\text { Competence }\end{array}$ & $\begin{array}{l}\text { - Kesadaran individu } \\
\text { bahwa dia dapat } \\
\text { mengatasi segala } \\
\text { tantangan dan masalah } \\
\text { yang dihadapi dengan } \\
\text { kemampuan, usaha } \\
\text { serta caranya sendiri }\end{array}$ & $\begin{array}{l}\text { - Mempercayai akan } \\
\text { kemampuan dirinya dalam } \\
\text { bidang akademik maupun } \\
\text { non akademik } \\
\text { - Mampu mengatur waktu } \\
\text { antara belajar sekolah dan } \\
\text { aktivitas lainnya }\end{array}$ & $\begin{array}{l}\text { - Siswa percaya akan } \\
\text { kemampuan dirinya dalam } \\
\text { bidang akademik maupun non } \\
\text { akademik } \\
\text { - Siswa mampu mengatur waktu } \\
\text { antara belajar sekolah dan } \\
\text { aktivitas lainnya }\end{array}$ \\
\hline $\begin{array}{l}\text { Evaluasi dan } \\
\text { tindak lanjut }\end{array}$ & $\begin{array}{l}\text { - Kesiapan siswa } \\
\text { dalam } \\
\text { mengakhiri } \\
\text { kegiatan KKp }\end{array}$ & $\begin{array}{l}\text { - Mengetahui sejauh } \\
\text { mana perubahan yang } \\
\text { terjadi pada anggota } \\
\text { setelah diberikan } \\
\text { perlakuan mengikuti } \\
\text { kegiatan KKp }\end{array}$ & $\begin{array}{l}\text { - Anggota kelompok mengisi } \\
\text { skala psikilogis }\end{array}$ & $\begin{array}{l}\text { - Anggota mampu menerapkan } \\
\text { keteampilan yang diperoleh } \\
\text { dari KKp } \\
\text { - Self esteem anggota menjadi } \\
\text { meningkat }\end{array}$ \\
\hline
\end{tabular}

Uji keefektifan model layanan konseling kelompok dengan teknik manjemen diri untuk meningkatkan self esteem siswa dianalisa dengan Uji wilcoxon melalui program SPSS. Syarat uji wilcoxon adalah perbedaan dua kelompok data berdistribusi normal.Peneliti terlebih dahulu harus melakukan dahulu uji normalitas pada perbedaan kedua kelompok tersebut. Peneliti melakukan uji normalitas dengan Shapiro Wilk dan diperoleh nilai signifikan sebesar $0,672$ ( $p>0,05)$ berarti data adalah tersebut normal. Selanjutnya dilakukan analisis dengan uji wilcoxon. Berikut ini akan diuraikan hasil rangkuman pengujian keefektifan model layanan konseling kelompok dengan teknik manajemen diri untuk meningkatkan self esteem siswa. Hasil uji wilcoxon dijelaskan pada tabel II.

TABEL II

HASIL UJI WILCOXON

$\begin{array}{r}\frac{\text { HASIL UJI WILCOXON }}{\text { Test Statistics }^{\mathbf{b}}} \\ \hline \mathrm{postes} \mathrm{-} \mathrm{pretes} \\ \hline \mathrm{P}\end{array}$

Asymp. Sig. (2-tailed) .026

a. Based on negative ranks.

b. Wilcoxon Signed Ranks Test
Keefektifan model konseling kelompok dengan teknik manajemen diri terlihat pada peningkatan self esteem siswa yang dapat dilihat dari perbandingan antara tingkat self esteem siswa sebelum diberikan layanan konseling kelompok (skor evaluasi awal) dan sesudah diberikan layanan konseling kelompok (skor evaluasi akhir). Perbandingan nilai evaluasi awal dan evaluasi akhir siswa secara rinci ditampilkan dalam tabel III dan grafik 1.

TABEL III

PERBANDINGAN SKOR EVALUASI AWALDAN EVALUASI AKHIR

\begin{tabular}{clcc}
\hline No & Siswa & pretes & Postes \\
\hline 1 & SGIA & 86 & 108 \\
2 & IKS & 104 & 117 \\
3 & IKSAP & 110 & 126 \\
4 & RARP & 120 & 133 \\
5 & DD & 117 & 130 \\
6 & HAW & 102 & 128 \\
\hline & Jumlah & 639 & 742 \\
\hline
\end{tabular}




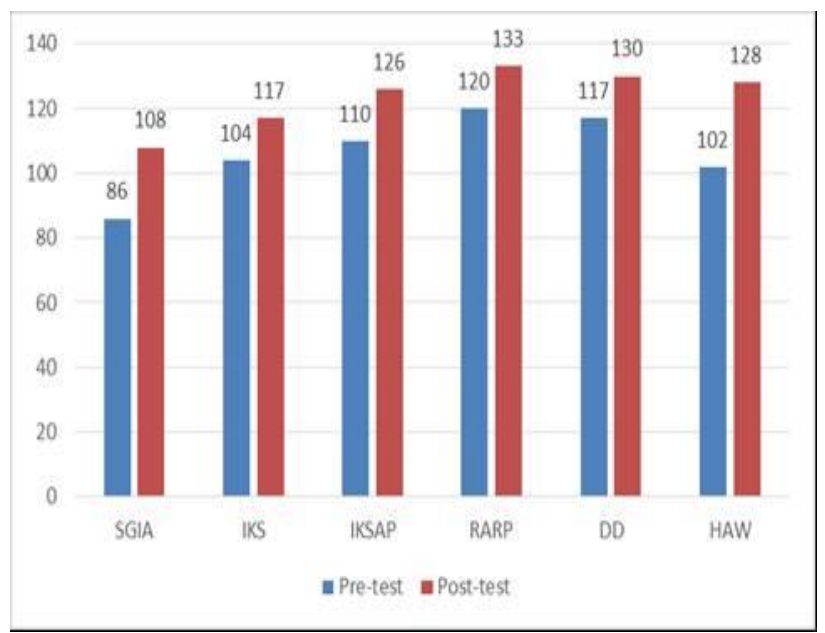

Grafik 1. Bentuk diagram batang pada hasil perbandingan skor evaluasi awal dan evaluasi akhirsiswa secara keseluruhan

Berdasarkan tabel II dan grafik 1, terlihat bahwa terjadi kenaikan skor self esteem siswa setelah diberikan layanan konseling kelompok dengan teknik manajemen diri dibandingkan dengan skor self esteem sebelum diberikan layanan konseling kelompok dengan teknik manajemen diri.

Secara keseluruhan, skor self esteem siswa mengalami kenaikan 103 poin atau sebesar 7,46\%. Peningkatan skor self esteem siswa tidak lepas dari proses yang dialami oleh siswa berupa dinamika kelompok yang terjadi dari setiap pertemuan dalam pelaksanaan konseling kelompok dengan teknik manajemen diri. Selain itu, kesediaan siswa untuk mengaplikasikan hal-hal baru serta manfaat yang diperoleh melalui kegiatan layanan konselingkelompok dengan teknik manajemen diri dalam kehidupan mereka sehari-hari memiliki kontribusi dalam peningkatan skor self esteem tersebut.

\section{B. PEMBAHASAN}

Self-esteem didefinisikan oleh Guindon [4] dan Mruk [5] sebagai sikap evaluatif seseorang terhadap dirinya; penilaian afektif individu terhadap konsep dirinya berdasarkan perasaan berharga dan merasa diterima, sebagai konsekuensi dari kesadarannya akan kompetensi dan umpan balik yang ia terima dari lingkungan sekitar. Jadi self esteem dapat dijelaskan adalah suatu aktifitas yang dilakukan oleh individu secara sadar serta memiliki komitmen ke arah yang positif untuk kemajuan individu tersebut dengan mengacu pada pengelolaan diri yang baik.

Konseling kelompok dengan teknik manajemen diri dapat digunakan dalam meningkatkan self esteem siswa. Dilakukan dalam situasi konseling kelompok dalam dinamika kelompok agar siswa efektif dalam mengungkapkan permasalahan mengenai self esteem secara bersama-sama dengan anggota lain. Pada tahap kegiatan dalam konseling kelompok, pemimpin kelompok akan memberikan strategi teknik manajemen diri untuk meningkatkan self esteem siswa yang terdiri dari self monitoring, self reward, self contracting, stimulus control [6].

Berdasarkan hasil analisis data dengan Uji wilcoxon menunjukkan bahwa tujuan dari model konseling kelompok dengan teknik manajemen diri untuk meningkatkan self esteem siswa telah tercapai, yakni dengan adanya perubahan dari hasil evaluasi awal dan hasil evaluasi akhir pada self esteemyang dimiliki siswa kelas X SMK PGRI 1 Denpasar.

Konseling kelompok dengan teknik manajemen diri berangkat dari hasil analisis kebutuhan (need assesment) sehingga relevan dengan kebutuhan di lapangan yang menunjukan perlunya upaya strategis dalam memberikan layanan yang berkualitas serta perlunya intervensi terhadap siswa yang terindikasi memiliki self esteem rendah. Hal yang sama sesuai dengan pernyataan Rusmana [7] yang menegaskan bahwa penyelenggaraan layanan konseling kelompok yang berkualitas melalui penerapan kegiatan dinamika kelompok yang efektif ditandai dengan hadirnya suasana kejiwaan yang sehat diantara peserta layanan, meningkatkan spontanitas, lahirnya perasaan yang positif, mampu meningkatkan minat untuk terlibat dalam seluruh proses kegiatan, memungkinkan terjadinya katarsis serta meningkatnya pengetahuan dan self esteem siswa.

Konseling kelompok dengan teknik manajemen diri memiliki kontribusi yang positif terhadap pelayanan bimbingan dan konseling di sekolah. Melalui konseling kelompok teknik manajemen diri, siswa mampu mengaktualisasikan diri sesuai potensi, bakat, dan minat yang dimilikinya.Hal tersebut mendukung penelitian ini untuk mengembangkan model konseling kelompok dengan teknik manajemen diri.

\section{KESIMPULAN}

Berdasarkan hasil analisis data, mulai dari tahap penelitian pendahuluan sampai pada uji coba model dapat dirumuskan beberapa kesimpulan sebagai berikut:

1. Pelaksanaan layanan konseling kelompok di SMK PGRI 1 Denpasar sudah dilaksanakan, akan tetapi kegiatan yang dilakukan di dalam setiap tahapannya belum efektif dan optimal. Tingkat self esteem siswa di SMK PGRI 1 Denpasar berada pada kategori rendah sebesar $7 \%$ yaitu 6 orang siswa dan kategori sangat rendah sebesar $3 \%$ yaitu 2 orang siswa.

2. Konseling kelompok dengan teknik manajemen diri efektif meningkatkan self esteem siswa. Konseling kelompok dengan teknik manajemen diri setelah diimplementasikan efektif untuk meningkatkan self esteem siswa skor rata-rata pada evaluasi awal dan evaluasi akhir dimanaself esteem siswa meningkat dari skor rata-rata sebelum dan sesudah diadakan konseling kelompok dengan teknik manajemen diri yaitu 103 poin. Hasil didukung data hasil perhitungan dengan uji ratarata uji wilcoxon yang menunjukkan nilai hitung 0,026 .

\section{SARAN}

1. Bagi Sekolah

Bagi sekolah khususnya SMK sebagai satuan pendidikan yang menyediakan konseling kelompok dan konseling 
mampu menyiapkan serta mengakomodasi kebutuhankebutuhan siswa terkait kemampuan dasar dan cita-cita siswa sehingga mampu memacu motivasi dan semangat belajarnya. Selalu membuka ruang kesempatan pada orang tua siswa terkait harapan dan keinginan yang sudah disepakati bersama anak. Mendorong dan terus memfasilitasi peserta didik untuk memahami self esteem yang akan memaksimalkan kemampuan yang dimiliki.

2. Bagi Guru Bimbingan dan Konseling

Dalam pelaksanaan bimbingan dan konseling salah satu aspek yang harus diperhatikan adalah self esteemsiswa yang di internalisasikan atau dipegang teguh oleh siswa. Karena pemahaman tentang self esteemtersebut sangat penting sehingga dalam upaya pemberian layanan konseling kelompok efektif dan self esteem harus tetap dijadikan acuan dalam menyelenggarakan layanan konseling kelompok. Selain itu Guru BK sekolah agar senantiasa dapat memfasilitasi perkembangan self esteem siswa, sebab self esteem merupakan salah satu kunci yang akan mengantarkan siswa pada sebuah keberhasilan.

3. Bagi Peneliti Selanjutnya

Hasil penelitian pengembangan konseling kelompok dengan teknik manajemen diri secara konseptual memberikan kontribusi yaitu sebagai perluasan khasanah keilmuan tentang konsep dan praktik bimbingan dan konseling khususnya dalam layanan konseling kelompok, yang dapat dijadikan salah satu referensi oleh peneliti di masa mendatang. Selain itu, bagi peneliti yang ingin melaksanakan penelitian mengenai self esteem siswa, agar penelitian ini dapat dikembangkan untuk mengkaji pada indikator perkembangan yang lain yang ada pada diri siswa.

\section{UCAPAN TERIMAKASIH}

Kami ingin mengucapkan terima kasih kepada Kepala SMK PGRI 1 Denpasar, Rektor IKIP PGRI, Ketua LP2M IKIP PGRI Bali, Dekan FIP IKIP PGRI Bali serta DRPM KEMENRISTEK DIKTI yang telah mendukung terlaksananya penelitian ini.

\section{DAFTAR PUSTAKA}

[1] Gibson, R.L. at all. (2011). Bimbingan dan Konseling. Yogyakarta: Pustaka Pelajar.

[2] Fauzan, L. (1992). Pengubahan Kebiasaan Belajar Siswa SMA dengan Siasat Kelola Diri. Malang: Tesis S2 FBS IKIP Malang: Tidak Diterbitkan.

[3] Sugiyono. (2013). Metode Penelitian Pendidikan (Pendekatan Kuantitatif, Kualitatif dan RnD). Bandung: Alfabeta.

[4] Guindon, M. H. (2010). Self-Esteem Across The Lifespan : Issues And Interventions. NY: Taylor and Francis Group

[5] Mruk, C. (2006). Self-esteem Research, Theory, And Practice: Toward A Positive Psychology Of Self-Esteem. NY : Springer Publishing Company

[6] Reasoner, R. W. (1982). Building Self-Esteem in Secondary Schools. Palo Alto: Consulting Psychologist Press, Inc.

[7] Rusmana, N. (2009). Permainan (Game \& Playing). Bandung : Rizk Pres. 